\title{
Update on the management of recurrent Cushing's disease
}

\author{
Martin J. Rutkowski, MD, ${ }^{1}$ Patrick M. Flanigan, BS, ${ }^{1}$ and Manish K. Aghi, MD, PhD1,2 \\ 1Department of Neurological Surgery, and ${ }^{2}$ Center of Minimally Invasive Skull Base Surgery and California Center for Pituitary \\ Disorders, University of California, San Francisco, California
}

\begin{abstract}
After transsphenoidal surgery, Cushing's disease (CD) shows excellent long-term remission rates, but it may recur and pose a therapeutic challenge. Findings in recent published reports on the treatment of recurrent adrenocorticotropic hormone (ACTH)-secreting tumors suggest that repeat resection, radiation-based therapies such as Gamma Knife surgery and proton-beam radiosurgery, pharmacotherapy, and bilateral adrenalectomy all have important roles in the treatment of recurrent $C D$. Each of these interventions has inherent risks and benefits that should be presented to the patient during counseling on retreatment options. Radiation-based therapies increasingly appear to have efficacies similar to those of repeat resection in achieving biochemical remission and tumor control. In addition, an expanding retinue of medication-based therapies, several of which are currently being evaluated in clinical trials, has shown some promise as tertiary adjunctive therapies. Lastly, bilateral adrenalectomy may offer durable control of refractory recurrent CD. An increasing number of published studies with long-term patient outcomes highlight the evolving treatment patterns in the management of recurrent $C D$.
\end{abstract}

http://thejns.org/doi/abs/10.3171/2014.11.FOCUS14703

KEY WORDS Cushing's disease; adenoma; adrenocorticotropic hormone; recurrent; radiation; surgery; radiosurgery; adrenalectomy

$\mathrm{C}$ USHING's disease (CD), first described by Harvey Cushing in 1932, is an uncommon disorder in which a pituitary adenoma leads to overproduction of adrenocorticotropic hormone (ACTH). This overproduction results in hypercortisolemia, causing symptoms such as hypertension, diabetes mellitus, cardiovascular disease, osteoporosis, thromboembolism, obesity, and depression. ${ }^{1}$ Women are disproportionately affected by CD, although men who have the disease are typically younger and display more severe symptoms. ${ }^{39}$ Prompt and accurate diagnosis of CD is critical because of the high morbidity and mortality rates associated with its natural history; mortality rates of $\mathrm{CD}$ are estimated to be $50 \%$ at 5 years in untreated individuals. ${ }^{54}$

Once CD is diagnosed, endonasal transsphenoidal resection provides an excellent first-line intervention that removes ACTH-producing cells while preserving native pituitary function. Remission rates of CD have been extensively studied and range from $69 \%$ to $93 \%$, with a median or mean time to recurrence ranging from 20 to 84 months. ${ }^{1,57}$ Importantly, initial resection fails to achieve remission in
$7 \%-31 \%$ of patients, and the disease will recur in 3\%-22\% of patients after $>3$ years, ${ }^{1-3,10,11,16,21,22,24,25,37,43,44,46,47,50,51,66} \mathrm{a}$ rate that can approach $20 \%-25 \%$ at 10 years postoperatively. ${ }^{57}$ These observations highlight the importance of long-term surveillance for recurrence of $\mathrm{CD}$. The diagnosis of recurrence involves use of similar biochemical testing as used at the time of the original diagnosis, including measurement of urinary free cortisol, of serum cortisol after a dexamethasone-suppression test, or of latenight salivary cortisol. The dexamethasone-suppressed corticotropin-releasing hormone stimulation test may be used for equivocal cases of CD. ${ }^{30}$ Because cortisol levels often fluctuate, and results sometimes vary across multiple measurements even in the same patient, repeat testing is recommended..$^{30,40,57}$ Dynamic MRI of the pituitary gland may be used to identify recurrent ACTH-secreting pituitary adenomas. Bilateral inferior petrosal sinus sampling is typically not used to evaluate recurrent CD because the venous drainage of the pituitary gland lateralizes unpredictably after initial surgery.

There is little consensus on predictors of $\mathrm{CD}$ recur- 
rence; tumor size, location, and surgeon experience have been posited as potential predictors, but have remained unproven in multiple studies. Here we review management strategies for recurrent $\mathrm{CD}$, including repeat transsphenoidal surgery, which is often the first-line treatment for recurrence; radiation with a particular emphasis on radiosurgery; and medical management with a particular emphasis on cabergoline, mifepristone, and the novel multireceptor ligand and somatostatin analog pasireotide (SOM230), which has produced encouraging results in a recently completed Phase III clinical trial.

\section{Methods \\ Literature Searches}

To identify recent advances in the diagnosis and management of recurrent $\mathrm{CD}$, we performed a comprehensive search of the published literature on PubMed. The following search terms were used: "Cushing," "Cushing's," "recurrent," "remission," "persistent," "radiosurgery," "MRI," "mifepristone," "ketoconazole," "adrenalectomy," "pasireotide," and "Nelson's syndrome." All reports identified in this search and published from the time of the senior author's (M.K.A.'s) last publication in 2008 on recurrent CD until 2014 were included for review, including abstracts and full-length publications. All publications on repeat resection and radiation-based treatments described cases of recurrent $\mathrm{CD}$ rather than cases of persistent disease. Recurrent CD was defined as the presence of hypercortisolemia immediately after the primary treatment. However, the primary treatment for these patients upon initial diagnosis of $\mathrm{CD}$ was not uniform: some patients received primary surgery and some received primary radiation-based strategies after a biochemical diagnosis of $\mathrm{CD}$.

\section{Results and Discussion \\ Repeat Transsphenoidal Surgery}

We identified 4 studies (Table 1) published between 2008 and 2014 that had available outcomes data for patients who had recurrent CD; the studies' cohort sizes ranged from 8 to 40 patients. ${ }^{22,30,38,61}$ In the largest series, recurrent $\mathrm{CD}$ was diagnosed as elevated 24-hour urinary free cortisol with symptoms consistent with the disease in 40 patients; for 36 of these, patient outcomes data were available. ${ }^{38}$ The patients were offered repeat surgery only when the recurrent tumor was evident on MRI scans or when a centralized ACTH gradient was identified on inferior petrosal sinus sampling and with high-dose dexamethasone suppression. The median time to recurrence after the initial transsphenoidal surgery was 3 years. After repeat resection, they defined tumor remission as normal levels of 24-hour urinary free cortisol postoperatively or as a need for continued glucocorticoid replacement. In total, 24 patients $(67 \%)$ underwent selective adenectomy, and of these, 1 (2.8\%) underwent hemihypophysectomy, 6 (17\%) underwent subtotal hypophysectomy, and $5(14 \%)$ underwent total hypophysectomy. In 22 patients (61\%) the disease was in remission; of note, when compared with the original cohort of patients who underwent first-time resection (and in whom remission was 85\%), the failure rates were $39 \%$ for repeat surgery and $15 \%$ for primary surgery.
This difference highlighted that the efficacy of repeat surgery for treating $\mathrm{CD}$ does not match that of primary surgery. The 14 patients who had persistent $C D$ were treated with radiosurgery, ketoconazole, and bilateral adrenalectomy. Only the presence of a recurring tumor larger than $1 \mathrm{~cm}$ (macroadenoma) had a statistically significant and inverse association with remission: remission failed in all 3 patients who showed symptoms of macroadenoma recurrence. ${ }^{38}$

In another large series of 35 patients, ${ }^{22}$ remission was observed in only 13 patients $(37 \%)$ after repeat transsphenoidal surgery, and tumors recurred on average 73 months after the primary operation. Nineteen $(86 \%)$ of 22 unsuccessfully treated patients were further treated with bilateral adrenalectomy (36\%), with radiotherapy (41\%), or with a combination of those 2 modalities (9\%). The authors noted that similar to the findings by Patil et al., ${ }^{37}$ macroadenomas were significantly more likely to be associated with recurrence than microadenomas: 16 of 39 macroadenomas (41\%) versus 73 of 330 microadenomas $(22 \%)$ recurred. Similar to what has been noted in earlier studies with extended follow-up, ${ }^{1,15,29,35,37}$ both early $(<5$ years) and late ( $>5$ years) recurrences were observed. ${ }^{22}$

Finally, in 2 smaller series of 8 patients $^{61}$ and 10 patients ${ }^{5}$ with recurrent $\mathrm{CD}$, mean times to recurrence were 74 months and 35 months, respectively. In the 10-patient series, remission rates after repeat surgery were $50 \%$ for macroadenomas and $83 \%$ for microadenomas. ${ }^{5}$

Across the studies included here, complications were incompletely reported, but when noted they included diabetes insipidus, CSF leak, infection, cavernous sinus hemorrhage, carotid artery injury, and need for partial or total hormone replacement for panhypopituitarism. Probably because of the relatively small numbers of recorded and reported recurrences of $\mathrm{CD}$, the identification of factors significantly associated with recurrence remained elusive. The 2 larger series reported higher rates of recurrence in cases of macroadenomas than in cases of microadenomas, ${ }^{38,22}$ but recurrence did not appear to be associated with age, sex, MRI-based tumor identification, or extent of resection. Furthermore, Wagenmakers et al. found no statistically significant differences in remission or recurrence for patients undergoing repeat resection, including MRI-based tumor identification, age, sex, and time interval between primary and repeat resections. ${ }^{61}$

\section{Radiation-Based Therapies for Recurrent CD}

An increasing number of radiation-based therapies are now used in the treatment of pituitary adenomas, including fractionated radiotherapy and stereotactic radiotherapies such as Gamma Knife surgery (GKS), CyberKnife, and proton-beam therapy. Accordingly, the recent literature reflects a greater focus on these treatment strategies as a means for achieving tumor control and disease remission in recurrent CD. . $19,32,58$ Such strategies are important for adjuvant or salvage therapy for patients in whom repeat resection was unsuccessful or who seek noninvasive treatments. They are also relevant for treating tumors that cannot be repeatedly resected because of cavernous sinus invasion or equivocal appearance on MRI scans.

Gamma Knife surgery has largely replaced conven- 
TABLE 1. Studies published between 2008 and 2014 with available data on outcomes after repeat transsphenoidal surgery for recurrent CD

\begin{tabular}{|c|c|c|c|c|c|}
\hline Authors \& Year & $\begin{array}{l}\text { No. of Pts w/ } \\
\text { Tumor Recurrence } \\
\text { Undergoing } \\
\text { Repeat Op }\end{array}$ & Recurrence Criteria & $\begin{array}{l}\text { Remission } \\
\text { After } \\
\text { Repeat } \\
\text { Op (\%) }\end{array}$ & $\begin{array}{l}\text { Length } \\
\text { of FU } \\
\text { (mos) }\end{array}$ & Remission Criteria \\
\hline Patil et al., $2008^{38}$ & 36 & $\begin{array}{l}\text { Normal } 24 \text {-hr UFC for at least } 3 \text { mos } \\
\text { before subsequent recurrence }\end{array}$ & 61 & 36 & $\begin{array}{l}\text { Normal postop 24-hr UFC or continued } \\
\text { need for glucocorticoid replacement }\end{array}$ \\
\hline Hofmann et al., 2008 & 35 & Abnormal DST results & 37 & - & Normal DST results \\
\hline $\begin{array}{l}\text { Wagenmakers et al., } \\
2009\end{array}$ & 8 & $\begin{array}{l}\text { Development of clinical symptoms of } \\
\text { hypercortisolism \& inadequate } \\
\text { suppression of plasma cortisol level } \\
\text { after o/n 1-mg DST }\end{array}$ & 88 & 31 & $\begin{array}{l}\text { Disappearance of symptoms of hypercorti- } \\
\text { solism w/ basal plasma cortisol level } \leq 50 \\
\text { nmol/L } 24-48 \text { hrs after glucocorticoid } \\
\text { withdrawal \&/or suppression of plasma } \\
\text { cortisol level } \leq 50 \mathrm{nmol} / \mathrm{L} \text { after o/n } 1 \text {-mg } \\
\text { DST w/in the first } 3 \text { mos after transsphe- } \\
\text { noidal op }\end{array}$ \\
\hline Liubinas et al., 2011 & 14 & Abnormal serum \&/or UFC levels & 79 & - & Normalization of serum \&/or UFC levels \\
\hline
\end{tabular}

DST = dexamethasone suppression test; FU = follow-up; o/n = overnight; Pts = patients; UFC = urinary free cortisol; - = information unavailable.

tional fractionated radiation therapy after the latter failed to control initial or recurrent $\mathrm{CD}$. Because radiosurgery has been shown to achieve better tumor control and biochemical remission and to have an improved safety profile, many authors have advocated for its use to treat recurrent $\mathrm{CD}^{1,27}$ Used as far back as in the 1950s for pituitary tumors, GKS has proven effective in the treatment of CD since the 1970 s to $1980 \mathrm{~s} .{ }^{14}$ Since 2000 , the rates of remission after GKS for recurrent or persistent $\mathrm{CD}$ have ranged from $17 \%$ to $54 \% .^{2}$ Studies published since 2008 suggest a trend toward improved rates of remission, with longer follow-up periods and greater patient numbers than previously reported in the literature.

In the largest series available, Sheehan et al. present their experience with 96 patients. ${ }^{49}$ The median follow-up period was 4 years, and overall remission was $70 \%$ with a median time to remission of 16.6 months. The mean target volume was $1.8 \mathrm{~cm}^{3}$ with a mean margin dose of 22 Gy and a mean maximum dose of 47.2 Gy. Although the results were somewhat obscured by the previous use of radiotherapy in 6 patients $(6 \%)$ and by an unclear primary treatment strategy of transsphenoidal surgery, open craniotomy, or initial radiosurgery, the authors reported similarly high rates of radiological response, with $70 \%$ of the tumors exhibiting a decreased size, $28 \%$ a stable size, and only $2 \%$ an increased size. Notably, patients receiving ketoconazole during GKS treatment had a significantly longer time to remission than those who did not receive the drug (21.8 vs 12.6 months, $\mathrm{p}<0.012$ ). Recurrence after radiosurgically induced remission was observed in $15.6 \%$ of the patients, partial loss of pituitary function in $36 \%$, and cranial neuropathies in $5.2 \%$.

In another study examining patients with $\mathrm{CD}$, prolactinomas, or acromegaly, ${ }^{26}$ ACTH-secreting adenomas showed the most favorable response to GKS, with $35 \%$ of 30 patients having normalization of cortisol levels. Gamma Knife surgery also normalized prolactin levels in $17.4 \%$ of 27 patients who had prolactinoma and growth hormone levels in $4.8 \%$ of 67 patients who had acromegaly. The study had a mean follow-up period of $\geq 3$ years, and tumor control was $100 \%$ across all 3 groups. ${ }^{26}$ In an- other large study of 49 patients, GKS treatment achieved a $66 \%$ remission rate by 5 years postradiosurgery, with one-half of the treated patients exhibiting remission within 3-4 years..$^{32}$ A comprehensive summary of recent radiosurgery studies, including those with smaller case series, is shown in Table 2.

The most recent study of GKS treatment for CD and Nelson's syndrome included 26 patients who were followed up for a mean length of 99 months. ${ }^{33}$ Seventeen patients underwent primary resection, and 9 underwent prior radiosurgery. Of note, all patients in this series were given medication (ketoconazole combined first with metyrapone and then with cabergoline as needed) before and after radiosurgery until ACTH levels normalized. Similar to the observations by Sheehan et al.,49 the results for patients who had CD were encouraging: in $81 \%$ of the patients, cortisol levels normalized at a median time of 30 months, and none of the patients had CD recurrence. Furthermore, radiographic follow-up between 2 and 5 years posttreatment revealed tumors that remained stable (8\%), had decreased in size (62\%), or had resolved completely (31\%) without any evidence of regrowth. Patients who showed Nelson's syndrome had lower rates of ACTH normalization (2 [14.3\%] of 14 patients), and radiographic follow-up over the same 2- to 5-year period indicated regrowth of 1 tumor (9\%), an unchanged size for 3 tumors $(27 \%)$, a decreased size for 5 tumors (45\%), and disappearance of 2 tumors (18\%). Another small series on the outcomes of radiosurgical treatment for Nelson's syndrome followed 10 patients over a mean period of 7 years and also noted abrogated tumor growth in all patients and normalization of ACTH levels in 1 patient $(10 \%){ }^{60}$ It has been suggested that radiosurgery before bilateral adrenalectomy may efficiently reduce the onset of Nelson's syndrome. ${ }^{34}$ In a study by Hornyak and colleagues, including Dr. Nelson after whom the syndrome is named, the authors recommended resection as the primary therapy, reoperation for recurrent tumors, radiation for unresectable disease, and adrenalectomy as a last resort. ${ }^{23}$

Comparing the results of studies that have used different radiation modalities is difficult because of variations in the 
TABLE 2. Studies published between 2008 and 2014 with available data on outcomes after radiosurgery for CD*

\begin{tabular}{|c|c|c|c|c|c|c|}
\hline Authors \& Year & $\begin{array}{l}\text { No. of Pts wl } \\
\text { Tumor } \\
\text { Recurrence } \\
\text { Undergoing RT }\end{array}$ & Recurrence Criteria & $\begin{array}{l}\text { Treatment } \\
\text { Modality }\end{array}$ & $\begin{array}{l}\text { Remission } \\
\text { After RT (\%) }\end{array}$ & $\begin{array}{l}\text { Length } \\
\text { of FU } \\
\text { (mos) }\end{array}$ & Remission Criteria \\
\hline Petit et al., 2008 & $33 \dagger$ & - & $\begin{array}{l}\text { Proton-beam } \\
\text { SRS }\end{array}$ & 52 & 14 & $\begin{array}{l}\text { Sustained ( } 3 \text { mos) normalization of UFC af- } \\
\text { ter completion of washout period during } \\
\text { which medical therapy was withdrawn }\end{array}$ \\
\hline $\begin{array}{l}\text { Castinetti et al., } \\
2009\end{array}$ & 18 & Abnormal DST levels & GKS & 50 & 28 & $\begin{array}{l}\text { Normalized } 24-\mathrm{hr} \text { UFC w/ suppressible } \\
\text { plasma cortisol level (<50 nmol/L) after } \\
\text { low-dose DST }\end{array}$ \\
\hline Swords et al., 2009 & 4 & - & GKS & 50 & 27 & $\begin{array}{l}\text { Mean serum cortisol levels obtained from } 5 \\
\text { samples taken from } 9 \text { AM to } 7 \text { PM }\end{array}$ \\
\hline Castro et al., 2010 & 9 & - & GKS & 66 & - & Normal serum ACTH level \\
\hline Losa et al., 2010 & 49 & - & GKS & 53 & - & Normal 24-hr UFC \\
\hline Wein et al., 2012 & 17 & - & SRS & 59 & 23 & $\begin{array}{l}\text { Normal UFC levels w/o cortisol-lowering } \\
\text { medications }\end{array}$ \\
\hline $\begin{array}{l}\text { Sheehan et al., } \\
2013\end{array}$ & 96 & $\begin{array}{l}\text { Abnormal serum cor- } \\
\text { tisol, ACTH \& } 24-h r \\
\text { UFC }\end{array}$ & GKS & 70 & $\begin{array}{c}12.6 \neq \& \\
21.8\end{array}$ & $\begin{array}{l}\text { Normal } 24 \text {-hr UFC \& normal morning se- } \\
\text { rum cortisol levels }\end{array}$ \\
\hline Lee et al., 2014 & 64 & - & $\begin{array}{l}\text { GKS (whole } \\
\text { sellar) }\end{array}$ & 71 & 10 & $\begin{array}{c}\text { Normal age- \& sex-appropriate UFC }(<45 \\
\text { mg/24 hrs) \& off medication for } 2 \text { mos }\end{array}$ \\
\hline Marek et al., 2014 & 26 & - & GKS & 81 & 78 & $\begin{array}{l}\text { Normal 24-hr UFC, morning serum cortisol, } \\
\quad \text { \& morning ACTH }\end{array}$ \\
\hline Verma et al., 2014 & 5 & - & RT & 20 & 55 & - \\
\hline Wattson et al., 2014 & 74 & - & $\begin{array}{l}\text { Proton-beam } \\
\text { SRS }\end{array}$ & $\begin{array}{l}54 \text { at } 36 \text { mos; } \\
67 \text { at } 60 \text { mos }\end{array}$ & 47 & $\begin{array}{l}\text { Biochemical complete response defined as } \\
>3 \text { mos of normal lab values w/o medical } \\
\text { treatment }\end{array}$ \\
\hline Wilson et al., 2014 & 41 & $\begin{array}{l}\text { Elevated morning se- } \\
\text { rum cortisol level } \\
>140 \mathrm{nmol} / \mathrm{L} \text { or } \\
\text { elevated } 24-\mathrm{hr} \text { UFC } \\
>276 \mathrm{nmol} / 24 \mathrm{hrs}\end{array}$ & LINAC & 25 & - & $\begin{array}{l}\text { Normal } 24-h r \text { UFC \& normal morning se- } \\
\quad \text { rum cortisol levels }\end{array}$ \\
\hline
\end{tabular}

LINAC = linear accelerator; NS = Nelson's syndrome; RT = radiotherapy.

* In all studies, most patients underwent initial resection; in some of the studies, tumors were initially treated with radiosurgery or repeat treatments were performed for persistent disease after an initial treatment.

$\dagger$ The patients showed persistent CD after the primary surgery.

$\ddagger$ Time to remission was 12.6 months in patients off ketoconazole and 21.8 months in patients on ketoconazole.

criteria for remission and in the comanagement of recurrence with medical therapy. Nonetheless, insight gleaned from the past 2 decades of published studies suggests that multiple radiation modalities are similarly successful in achieving tumor control and biochemical remission of CD. Remission rates of $89 \%-100 \%$ have been reported for patients treated with fractionated radiotherapy or radiosurgery, ${ }^{31,53}$ although radiosurgery appears to provide earlier remission than fractionated radiotherapy-based therapy. ${ }^{13,17,34,48}$ While complications arising from radiation-based modalities are inevitable, studies have shown that radiosurgery can be used safely: reduction of the margin radiation dose and avoidance of tumors with suprasellar extension may help prevent hypopituitarism, ${ }^{28,65}$ which can reach $32 \%$ at 5 years postradiosurgery. ${ }^{65}$ Neurocognitive decline, stroke, and secondary neoplasms appear to be rare complications, and are more associated with fractionated radiotherapy than with radiosurgery. ${ }^{6,748,56}$

Proton-beam radiosurgery is a promising and relatively new modality in the treatment of pituitary adenomas including $\mathrm{CD}$. It enables better dose distribution than GKS, and early findings suggested that it decreases rates of cranial neuropathy and tumor recurrence. ${ }^{41,52}$ The most recent and largest examination of proton-beam radiosurgery for $\mathrm{CD}$ treatment showed a biochemical tumor remission rate of $67 \%$ at the 5-year follow-up in 74 patients, with a median time of 32 months for demonstrated remission. Most intriguing was the observation that ACTH-secreting adenomas showed a significantly faster response to therapy in terms of time to remission than other functional adenoma subtypes. Furthermore, tumor control rates were excellent (98\%), although this included all subtypes, and data specific for patients who had CD were not reported. Rates of posttreatment hypopituitarism after proton-beam radiosurgery were higher (57\%) than after GKS treatment, but the limited number of studies on proton-beam radiosurgery makes accurate comparisons difficult. 


\section{Pharmacotherapy}

For patients unresponsive to or intolerant of repeat resection or radiation-based treatments, 3 classes of medications are available as adjuvant therapies. Drugs such as ketoconazole, metyrapone, and aminoglutethimide represent a group of antisteroidogenesis agents that may help prevent hypercortisolemia, blocking cytochrome p450 enzymes (in the cases of ketoconazole and etomidate), 11 $\beta$ hydroxylase (metyrapone), and cholesterol side cleavage (aminoglutethimide). ${ }^{1}$ Second, agents that indirectly block ACTH production have some utility, including pasireotide and cabergoline. Third, mifepristone provides efficacious treatment of CD because it blocks the glucocorticoid receptor directly. It also showed a significant benefit in glucose control and blood pressure in SEISMIC (Study of the Efficacy and Safety of Mifepristone in the Treatment of Endogenous Cushing's Syndrome), a multicenter study of 50 patients with Cushing's syndrome in whom multimodality treatments had failed..$^{18}$ At present, treatment with medications is reserved for patients in whom surgery fails to control the tumor either at diagnosis or at recurrence or for patients who are awaiting remission after radiosurgery. The relative efficacy of pharmacotherapy for achieving tumor control and biochemical remission remains unclear.

Of note, pasireotide, cabergoline, and mifepristone have been studied in detail and show promising results for the management of recurrent $\mathrm{CD}$ in several studies outlined in the following. In 2012, a group of investigators published the results of a 12-month, Phase III trial of pasireotide (SOM230) ${ }^{12}$ a somatostatin-receptor inhibitor with activity against receptor Subtypes 1-3 and particularly against Subtype 5. Pasireotide has demonstrated efficacy in lowering cortisol levels in patients who have CD. Patients included those in whom the disease was persistent after an initial round of therapy, and those who had recurrent tumors or who had a newly diagnosed disease, but were not considered candidates for surgery. The criteria for a diagnosis of $\mathrm{CD}$ were a mean 24-hour urinary free cortisol level 1.5 times the upper limit of normal levels, a morning corticotropin concentration of $5 \mathrm{ng} / \mathrm{L}$, and a confirmed tumor in the pituitary gland. The patients were randomized to receive either $600 \mu \mathrm{g}$ or $900 \mu \mathrm{g}$ pasireotide twice daily. Fifty of 103 patients (48\%) showed reductions in urinary free cortisol levels 6 months after these treatments such that their levels were normalized or at least $50 \%$ decreased from the pretreatment baseline. ${ }^{12}$ The effect was more pronounced in patients who had lower baseline urinary free cortisol levels, but a beneficial effect was also noted in patients who had higher baseline cortisol levels. Importantly, signs and symptoms of $\mathrm{CD}$ were also improved, including weight, blood pressure, LDL (lowdensity lipoprotein) cholesterol levels, and quality of life scores. Gastrointestinal upset and hyperglycemic events were the most common adverse effects, and only $6 \%$ of the patients discontinued the drug because of these effects. ${ }^{12}$ On the basis of these results, the FDA approved pasireotide for the treatment of patients who have CD and who cannot be surgically treated.

Cabergoline is used in the treatment of hyperprolactinemia; it is a $\mathrm{D}_{2}$ receptor agonist that has recently been studied for use in the treatment of CD. In a study of the short and long-term effectiveness of cabergoline in the treatment of $\mathrm{CD},{ }^{20} 30$ patients were followed up, including 3 patients treated with cabergoline primarily. The other 27 patients had unspecified recurrent or persistent CD. A complete response (defined as restoration of normal urinary free cortisol) was noted in 11 of the patients (37\%) and a partial response (defined as urinary free cortisol $<125 \%$ of the upper limit of normal) in 4 of the patients (13\%), together representing $50 \%$ of the 30 -patient cohort. Nine of the 11 full responders (82\%) maintained normal cortisol levels after a mean treatment duration of 37 months and exhibited regression of clinical signs and symptoms of the disease. Interestingly, the cabergoline treatment failed in 2 patients (7\%) after 2 years of complete normalization of urinary free cortisol. Initial tumor size, ACTH levels, degree of hypercortisolemia, and timing of cabergoline initiation before or after surgery did not correlate with treatment response. ${ }^{20}$

Importantly, this study represented patients from a variety of treatment approaches and disease scenarios (primary medical treatment and persistent or recurrent disease following surgical treatment), and it may be difficult to draw conclusions from this relatively small and mixed cohort. The authors' results mirror those from the study of Pivonello et al:: in that study, $8(40 \%)$ of 20 patients who had recurrent or persistent $\mathrm{CD}$ after initial surgery exhibited normal urinary free cortisol after cabergoline treatment, 4 patients (20\%) had tumor shrinkage, and most of the patients showed improvements in hypertension and glucose intolerance after the treatment. ${ }^{42}$

The SEISMIC study ${ }^{18}$ examined the efficacy of mifepristone, a progesterone-receptor antagonist with known glucocorticoid receptor antagonist activity, in treating 43 patients who had CD. In this 24-week, open-label multicenter study of daily oral administration of mifepristone, blood glucose levels and hypertension were assessed as primary end points. Twenty-six (60\%) of the patients showed at least a $25 \%$ drop in their area under the curve for glucose during 2-hour oral glucose tolerance testing at Week 24 of treatment, and had associated secondary benefits in decreased glycated hemoglobin (HgbAlc) and fasting plasma glucose. Additionally, 16 (38\%) of the patients showed a drop in diastolic blood pressure of at least $5 \mathrm{mmHg}$. Further improvements were seen in weight loss, waist circumference, insulin resistance, depression, cognition, and quality of life. Among the 17 patients who had $\mathrm{CD}$ and visible tumors on MRI scans after initial surgery, tumor control was observed in 16 patients $(94 \%)$ at 10 weeks and 24 weeks postenrollment. ${ }^{18}$

The novel 11ß-hydroxylase inhibitor LCI699 is also receiving attention for its effect on urinary cortisol levels. In a recent study, patients whose CD was diagnosed biochemically (as urinary free cortisol levels $>1.5$ the upper limit of normal) or those whose CD was histologically confirmed after resection received LCI699 for 10 weeks. All of the 12 patients enrolled exhibited reduction in their urinary free cortisol levels below the upper limit of normal or showed at least a $50 \%$ decrease from their baseline levels. ${ }^{4}$ The specific efficacy of this agent for recurrent CD remains unclear. 


\section{Bilateral Adrenalectomy}

As a final resort, bilateral adrenalectomy, typically performed laparoscopically, may be used as a definitive treatment of hypercortisolemia in patients who have recurrent $\mathrm{CD}$ and in whom surgical, radiation, and pharmacotherapy-based strategies have failed or who are intolerant of the side effects of these treatment modalities. Despite the need for long-term mineralocorticoid and glucocorticoid replacement, recent studies suggest bilateral adrenalectomy is a treatment that provides durable long-term outcomes. However, its safety is a matter of debate: results from 20 studies of 505 patients treated for CD showed that during a median follow-up period of 49 months, bilateral adrenalectomy had a median mortality rate of $9 \%$ due to causes including stroke, myocardial infarction, and sepsis. ${ }^{45}$ In this systematic review, $\mathrm{CD}$ and Cushing's syndrome were not disaggregated for analyses of biochemical outcome, but the overall rates of resolution of hypercortisolemia in the 7 included studies were $100 \%$ in 2 studies, and $3 \%$, $21 \%, 24 \%, 27 \%$, and $34 \%$ in the others.

In another study of long-term outcomes of bilateral adrenalectomy, 36 patients were followed up for a median period of 11 years. ${ }^{36}$ In total, 23 patients (63\%) experienced $\geq 1$ adrenal crises, and 9 patients $(24 \%)$ developed Nelson's syndrome. Notably, the mortality rate was also high (that is, 14\%). All of the 36 patients showed tumor remission without relapse. Importantly, significant reductions were seen in blood pressure, diabetes mellitus, physical stigmata, and muscular weakness. The relatively high mortality rates associated with bilateral adrenalectomy underscore that the intervention should be undertaken as a last resort. Patients should be properly counseled on the risks and benefits of this procedure, especially if treatment strategies using radiation-based and pharmacotherapies are available and tolerated by the patients.

\section{Conclusions}

Given the high morbidity and mortality rates associated with $\mathrm{CD}$, prompt diagnosis and treatment are paramount, and this applies to both the initial diagnosis and the identification of recurrent $\mathrm{CD}$. The treatment of recurrent $\mathrm{CD}$ remains challenging, with recent evidence suggesting a wide variety of comparably effective strategies for managing recurrent tumors. When possible, repeat transsphenoidal resection should be the first step in retreatment, but patients should be counseled that the efficacy of the second operation in achieving biochemical remission is lower than that of the first operation. Radiation-based strategies may adequately match repeat surgery in achieving disease control and are probably more effective for tumors in the cavernous sinuses. Finally, medical therapy offers a useful adjunctive treatment and in many instances improves the rates of remission when combined with other therapies.

\section{References}

1. Aghi MK: Management of recurrent and refractory Cushing disease. Nat Clin Pract Endocrinol Metab 4:560-568, 2008

2. Aghi MK, Petit J, Chapman P, Loeffler J, Klibanski A, Biller BMK, et al: Management of recurrent and refractory Cush- ing's disease with reoperation and/or proton beam radiosurgery. Clin Neurosurg 55:141-144, 2008

3. Atkinson AB, Kennedy A, Wiggam MI, McCance DR, Sheridan B: Long-term remission rates after pituitary surgery for Cushing's disease: the need for long-term surveillance. Clin Endocrinol (Oxf) 63:549-559, 2005

4. Bertagna X, Pivonello R, Fleseriu M, Zhang Y, Robinson P, Taylor A, et al: LCI699, a potent $11 \beta$-hydroxylase inhibitor, normalizes urinary cortisol in patients with Cushing's disease: results from a multicenter, proof-of-concept study. $\mathbf{J}$ Clin Endocrinol Metab 99:1375-1383, 2014

5. Blevins LS Jr, Sanai N, Kunwar S, Devin JK: An approach to the management of patients with residual Cushing's disease. J Neurooncol 94:313-319, 2009

6. Brada M, Burchell L, Ashley S, Traish D: The incidence of cerebrovascular accidents in patients with pituitary adenoma. Int J Radiat Oncol Biol Phys 45:693-698, 1999

7. Brada M, Ford D, Ashley S, Bliss JM, Crowley S, Mason M, et al: Risk of second brain tumour after conservative surgery and radiotherapy for pituitary adenoma. BMJ 304:13431346,1992

8. Castinetti F, Nagai M, Morange I, Dufour H, Caron P, Chanson $\mathrm{P}$, et al: Long-term results of stereotactic radiosurgery in secretory pituitary adenomas. J Clin Endocrinol Metab 94:3400-3407, 2009

9. Castro DG, Cecílio SAJ, Canteras MM: Radiosurgery for pituitary adenomas: evaluation of its efficacy and safety. Radiat Oncol 5:109, 2010

10. Chee GH, Mathias DB, James RA, Kendall-Taylor P: Transsphenoidal pituitary surgery in Cushing's disease: can we predict outcome? Clin Endocrinol (Oxf) 54:617-626, 2001

11. Chen JCT, Amar AP, Choi S, Singer P, Couldwell WT, Weiss MH: Transsphenoidal microsurgical treatment of Cushing disease: postoperative assessment of surgical efficacy by application of an overnight low-dose dexamethasone suppression test. J Neurosurg 98:967-973, 2003

12. Colao A, Petersenn S, Newell-Price J, Findling JW, Gu F, Maldonado M, et al: A 12-month phase 3 study of pasireotide in Cushing's disease. N Engl J Med 366:914-924, 2012

13. Colin P, Jovenin N, Delemer B, Caron J, Grulet H, Hecart $\mathrm{AC}$, et al: Treatment of pituitary adenomas by fractionated stereotactic radiotherapy: a prospective study of 110 patients. Int J Radiat Oncol Biol Phys 62:333-341, 2005

14. Degerblad M, Rähn T, Bergstrand G, Thorén M: Long-term results of stereotactic radiosurgery to the pituitary gland in Cushing's disease. Acta Endocrinol (Copenh) 112:310-314, 1986

15. Devoe DJ, Miller WL, Conte FA, Kaplan SL, Grumbach MM, Rosenthal SM, et al: Long-term outcome in children and adolescents after transsphenoidal surgery for Cushing's disease. J Clin Endocrinol Metab 82:3196-3202, 1997

16. Esposito F, Dusick JR, Cohan P, Moftakhar P, McArthur D, Wang C, et al: Clinical review: Early morning cortisol levels as a predictor of remission after transsphenoidal surgery for Cushing's disease. J Clin Endocrinol Metab 91:7-13, 2006

17. Estrada J, Boronat M, Mielgo M, Magallón R, Millan I, Díez $\mathrm{S}$, et al: The long-term outcome of pituitary irradiation after unsuccessful transsphenoidal surgery in Cushing's disease. $\mathbf{N}$ Engl J Med 336:172-177, 1997

18. Fleseriu M, Biller BMK, Findling JW, Molitch ME, Schteingart DE, Gross C: Mifepristone, a glucocorticoid receptor antagonist, produces clinical and metabolic benefits in patients with Cushing's syndrome. J Clin Endocrinol Metab 97:2039-2049, 2012

19. Ghostine S, Ghostine MS, Johnson WD: Radiation therapy in the treatment of pituitary tumors. Neurosurg Focus 24(5):E8, 2008

20. Godbout A, Manavela M, Danilowicz K, Beauregard H, Bruno OD, Lacroix A: Cabergoline monotherapy in the 
long-term treatment of Cushing's disease. Eur J Endocrinol 163:709-716, 2010

21. Hammer GD, Tyrrell JB, Lamborn KR, Applebury CB, Hannegan ET, Bell S, et al: Transsphenoidal microsurgery for Cushing's disease: initial outcome and long-term results. J Clin Endocrinol Metab 89:6348-6357, 2004

22. Hofmann BM, Hlavac M, Martinez R, Buchfelder M, Müller OA, Fahlbusch R: Long-term results after microsurgery for Cushing disease: experience with 426 primary operations over 35 years. J Neurosurg 108:9-18, 2008

23. Hornyak M, Weiss MH, Nelson DH, Couldwell WT: Nelson syndrome: historical perspectives and current concepts. Neurosurg Focus 23(3):E12, 2007

24. Invitti C, Pecori Giraldi F, de Martin M, Cavagnini F: Diagnosis and management of Cushing's syndrome: results of an Italian multicentre study. J Clin Endocrinol Metab 84:440 448, 1999

25. Knappe UJ, Lüdecke DK: Persistent and recurrent hypercortisolism after transsphenoidal surgery for Cushing's disease. Acta Neurochir Suppl 65:31-34, 1996

26. Kobayashi T: Long-term results of stereotactic gamma knife radiosurgery for pituitary adenomas. Specific strategies for different types of adenoma. Prog Neurol Surg 22:77-95, 2009

27. Kong DS, Lee JI, Lim H, Kim KW, Shin HJ, Nam DH, et al: The efficacy of fractionated radiotherapy and stereotactic radiosurgery for pituitary adenomas: long-term results of 125 consecutive patients treated in a single institution. Cancer 110:854-860, 2007

28. Lee CC, Chen CJ, Yen CP, Xu Z, Schlesinger D, Fezeu F, et al: Whole-sellar stereotactic radiosurgery for functioning pituitary adenomas. Neurosurgery 75:227-237, 2014

29. Leinung MC, Kane LA, Scheithauer BW, Carpenter PC, Laws ER Jr, Zimmerman D: Long term follow-up of transsphenoidal surgery for the treatment of Cushing's disease in childhood. J Clin Endocrinol Metab 80:2475-2479, 1995

30. Liubinas SV, Porto LD, Kaye AH: Management of recurrent Cushing's disease. J Clin Neurosci 18:7-12, 2011

31. Loeffler JS, Shih HA: Radiation therapy in the management of pituitary adenomas. J Clin Endocrinol Metab 96:19922003, 2011

32. Losa M, Picozzi P, Redaelli MG, Laurenzi A, Mortini P: Pituitary radiotherapy for Cushing's disease. Neuroendocrinology 92 (Suppl 1):107-110, 2010

33. Marek J, Ježková J, Hána V, Kršek M, Liščák R, Vladyka V, et al: Gamma knife radiosurgery for Cushing's disease and Nelson's syndrome. Pituitary [epub ahead of print], 2014

34. Mehta GU, Sheehan JP, Vance ML: Effect of stereotactic radiosurgery before bilateral adrenalectomy for Cushing's disease on the incidence of Nelson's syndrome. J Neurosurg 119:1493-1497, 2013

35. Nagesser SK, van Seters AP, Kievit J, Hermans J, van Dulken H, Krans HM, et al: Treatment of pituitary-dependent Cushing's syndrome: long-term results of unilateral adrenalectomy followed by external pituitary irradiation compared to transsphenoidal pituitary surgery. Clin Endocrinol (Oxf) 52:427-435, 2000

36. Oßwald A, Plomer E, Dimopoulou C, Milian M, Blaser R, Ritzel K, et al: Favorable long-term outcomes of bilateral adrenalectomy in Cushing's disease. Eur J Endocrinol 171:209-215, 2014

37. Patil CG, Prevedello DM, Lad SP, Vance ML, Thorner MO, Katznelson L, et al: Late recurrences of Cushing's disease after initial successful transsphenoidal surgery. J Clin Endocrinol Metab 93:358-362, 2008

38. Patil CG, Veeravagu A, Prevedello DM, Katznelson L, Vance ML, Laws ER Jr: Outcomes after repeat transsphenoidal surgery for recurrent Cushing's disease. Neurosurgery 63:266271,2008
39. Pecori Giraldi F, Moro M, Cavagnini F, Study Group on the Hypothalamo-Pituitary-Adrenal Axis of the Italian Society of Endocrinology: Gender-related differences in the presentation and course of Cushing's disease. J Clin Endocrinol Metab 88:1554-1558, 2003

40. Petersenn S, Newell-Price J, Findling JW, Gu F, Maldonado $\mathrm{M}$, Sen K, et al: High variability in baseline urinary free cortisol values in patients with Cushing's disease. Clin Endocrinol (Oxf) 80:261-269, 2014

41. Petit JH, Biller BMK, Yock TI, Swearingen B, Coen JJ, Chapman P, et al: Proton stereotactic radiotherapy for persistent adrenocorticotropin-producing adenomas. J Clin Endocrinol Metab 93:393-399, 2008

42. Pivonello R, De Martino MC, Cappabianca P, De Leo M, Faggiano A, Lombardi G, et al: The medical treatment of Cushing's disease: effectiveness of chronic treatment with the dopamine agonist cabergoline in patients unsuccessfully treated by surgery. J Clin Endocrinol Metab 94:223-230, 2009

43. Pouratian N, Prevedello DM, Jagannathan J, Lopes MB, Vance ML, Laws ER Jr: Outcomes and management of patients with Cushing's disease without pathological confirmation of tumor resection after transsphenoidal surgery. J Clin Endocrinol Metab 92:3383-3388, 2007

44. Rees DA, Hanna FWF, Davies JS, Mills RG, Vafidis J, Scanlon MF: Long-term follow-up results of transsphenoidal surgery for Cushing's disease in a single centre using strict criteria for remission. Clin Endocrinol (Oxf) 56:541-551, 2002

45. Ritzel K, Beuschlein F, Mickisch A, Osswald A, Schneider HJ, Schopohl J, et al: Clinical review: Outcome of bilateral adrenalectomy in Cushing's syndrome: a systematic review. J Clin Endocrinol Metab 98:3939-3948, 2013

46. Rollin GA, Ferreira NP, Junges M, Gross JL, Czepielewski MA: Dynamics of serum cortisol levels after transsphenoidal surgery in a cohort of patients with Cushing's disease. J Clin Endocrinol Metab 89:1131-1139, 2004

47. Rudnik A, Kos-Kudła B, Larysz D, Zawadzki T, Bazowski $P$ : Endoscopic transsphenoidal treatment of hormonally active pituitary adenomas. Neuroendocrinol Lett 28:438-444, 2007

48. Sheehan JP, Niranjan A, Sheehan JM, Jane JA Jr, Laws ER, Kondziolka D, et al: Stereotactic radiosurgery for pituitary adenomas: an intermediate review of its safety, efficacy, and role in the neurosurgical treatment armamentarium. J Neurosurg 102:678-691, 2005

49. Sheehan JP, Xu Z, Salvetti DJ, Schmitt PJ, Vance ML: Results of Gamma Knife surgery for Cushing's disease. J Neurosurg 119:1486-1492, 2013

50. Shimon I, Ram Z, Cohen ZR, Hadani M: Transsphenoidal surgery for Cushing's disease: endocrinological follow-up monitoring of 82 patients. Neurosurgery 51:57-62, 2002

51. Sonino N, Zielezny M, Fava GA, Fallo F, Boscaro M: Risk factors and long-term outcome in pituitary-dependent Cushing's disease. J Clin Endocrinol Metab 81:2647-2652, 1996

52. Stefan-Mikić S, Jovanović J, Jovanović N, Aleksić-Dordević M, Cvjetković D, Krajcir I: [Phamacoeconomic analysis of antibiotics use in the Clinical Center of Vojvodina.] Med Pregl 61 (Suppl 1):50-58, 2008 (Serbian)

53. Sun DQ, Cheng JJ, Frazier JL, Batra S, Wand G, Kleinberg LR, et al: Treatment of pituitary adenomas using radiosurgery and radiotherapy: a single center experience and review of literature. Neurosurg Rev 34:181-189, 2010

54. Sundaram NK, Carluccio A, Geer EB: Characterization of persistent and recurrent Cushing's disease. Pituitary 17:381391, 2014

55. Swords FM, Monson JP, Besser GM, Chew SL, Drake WM, Grossman AB, et al: Gamma knife radiosurgery: a safe and effective salvage treatment for pituitary tumours not con- 
trolled despite conventional radiotherapy. Eur J Endocrinol 161:819-828, 2009

56. Tooze A, Hiles CL, Sheehan JP: Neurocognitive changes in pituitary adenoma patients after gamma knife radiosurgery: a preliminary study. World Neurosurg 78:122-128, 2012

57. Tritos NA, Biller BMK, Swearingen B: Management of Cushing disease. Nat Rev Endocrinol 7:279-289, 2011

58. Vance ML: Cushing's disease: radiation therapy. Pituitary 12:11-14, 2009

59. Verma J, McCutcheon IE, Waguespack SG, Mahajan A: Feasibility and outcome of re-irradiation in the treatment of multiply recurrent pituitary adenomas. Pituitary 17:539-545, 2014

60. Vik-Mo EO, Øksnes M, Pedersen PH, Wentzel-Larsen T, Rødahl E, Thorsen F, et al: Gamma knife stereotactic radiosurgery of Nelson syndrome. Eur J Endocrinol 160:143-148, 2009

61. Wagenmakers MA, Netea-Maier RT, van Lindert EJ, Timmers HJ, Grotenhuis JA, Hermus AR: Repeated transsphenoidal pituitary surgery (TS) via the endoscopic technique: a good therapeutic option for recurrent or persistent Cushing's disease (CD). Clin Endocrinol (Oxf) 70:274-280, 2009

62. Wattson DA, Tanguturi SK, Spiegel DY, Niemierko A, Biller BMK, Nachtigall LB, et al: Outcomes of proton therapy for patients with functional pituitary adenomas. Int J Radiat Oncol Biol Phys 90:532-539, 2014

63. Wein L, Dally M, Bach LA: Stereotactic radiosurgery for treatment of Cushing disease: an Australian experience. Intern Med J 42:1153-1156, 2012
64. Wilson PJ, Williams JR, Smee RI: Cushing's disease: a single centre's experience using the linear accelerator (LINAC) for stereotactic radiosurgery and fractionated stereotactic radiotherapy. J Clin Neurosci 21:100-106, 2014

65. Xu Z, Lee Vance M, Schlesinger D, Sheehan JP: Hypopituitarism after stereotactic radiosurgery for pituitary adenomas. Neurosurgery 72:630-637, 2013

66. Yap LB, Turner HE, Adams CBT, Wass JA: Undetectable postoperative cortisol does not always predict long-term remission in Cushing's disease: a single centre audit. Clin Endocrinol (Oxf) 56:25-31, 2002

\section{Author Contributions}

Conception and design: Rutkowski, Aghi. Acquisition of data: Rutkowski, Flanigan. Analysis and interpretation of data: all authors. Drafting the article: all authors. Critically revising the article: Rutkowski, Aghi. Reviewed submitted version of manuscript: Rutkowski, Aghi. Administrative/technical/material support: Flanigan, Aghi. Study supervision: Aghi.

\section{Correspondence}

Martin J. Rutkowski, Department of Neurological Surgery, University of California, San Francisco, 505 Parnassus Ave., M-779, San Francisco, CA 94143. email: martin.rutkowski@gmail.com. 